\title{
Online supervision: a theory of supervisors' strategic communicative influence on student dissertations
}

\author{
Gunnar Augustsson · Jimmy Jaldemark
}

Published online: 26 May 2013

(c) Springer Science+Business Media Dordrecht 2013

\begin{abstract}
Online supervision mainly focuses on written communication and electronic drafts, while offline supervision comprises physical and social clues, verbal communication, and drafts of texts. This article focuses on supervisors' written online communication about drafts of undergraduate student dissertations. Theoretically, these utterances form part of the communicative exchanges performed in the practice of supervision. This means that supervision is an emergent phenomenon that relates to its past, current, and future states. The setting was a dissertation course within a bachelor programme in behavioural science. The data consists of 423 utterances from four supervisors. The utterances were analysed and categorised, and the results show different qualities and degrees of identifications in the supervisors' communicated utterances. The study shows that the quality of supervisors' utterances embraces the difference between the application of comments, points of view, instructions, and questions. This implicates the importance of supervisors' awareness of the nature and the combination of their utterances if they want to increase the student autonomy when supervising online.
\end{abstract}

Keywords Communication · Dissertation · Online learning · Supervision · Written utterances

\section{Supervision as a communicative practice}

Supervision is a relevant teaching practice for almost every student and teacher who participates in higher education. This practice includes supervisory meetings between students and teachers. During these meetings, students and teachers discuss drafts of the

\footnotetext{
G. Augustsson $(\bowtie) \cdot$ J. Jaldemark

Department of Education, Mid Sweden University, 87188 Härnösand, Sweden

e-mail: gunnar.augustsson@miun.se

J. Jaldemark

e-mail: jimmy.jaldemark@miun.se
} 
students' dissertation work (e.g., Stelma and Fay 2012). By participating in such practice, the students are supposed to perform academic work that they cannot do alone, or in the words of Vygotsky (1934/1987, p. 201), do "more in the intellectual sphere than he is capable of doing independently". Therefore, students' participation in this practice should develop their academic research and writing skills, as they learn from more experienced writers, such as the supervisor, and more knowledgeable peers, such as other students.

In the performance of this practice, the degree of symmetry in the relationship between students and supervisors could differ (Dysthe 2007). Supervisors could treat students as equal or assign them to some degree of subordination (e.g., Dysthe 2002b; Frankland 1999; Högberg et al. 1999; Kolmos et al. 2008; Parker 2009; Pearson and Brew 2002; Wisker et al. 2007). In this communicative practice, supervisors are expected to execute expert quality, embrace support for the students, and provide them with advice that could help them to balance both creativity and criticism (Anderson et al. 2006; Fraser and Mathews 1999). To meet these expectations, supervisors and students engage in oral or written communicative exchanges. In such a practice, learning relates to these communicative exchanges between students and supervisors. This article explores written aspects of these communicative exchanges by focusing on the ideas uttered by the supervisors on students' dissertation drafts.

However, the condition for performing written communication, discussed here in terms of utterances (see Bakhtin 1953/1986), on a student's work is a phenomenon that has gone through changes in recent decades. The emergence of computer-mediated communication is a feature that has opened new ways of distributing exchanges between students and supervisors. Moreover, enrolment in higher education is at a high level. For example, more students than ever before participate in higher education through computer-mediated communication. In the 2008-2009 academic year, for example, close to $30 \%$ of students-116,000 of 401,000 students - in the Swedish higher educational system were enrolled in courses or programs labelled as online education (Swedish National Agency for Higher Education and Statistics Sweden 2010). In the fall term of 2010, the United States (US) higher educational system had 6.1 million online students, approximately $31 \%$ of the students, an increase of 1.5 million students from the fall term of 2008 (Allen and Seamen 2010, 2011). The numbers from the Swedish and US systems show the growing influence of education mediated by computers in higher educational systems. In addition to students participating in online education, computer-mediated communication is also a part of campus-based higher education.

While the emphasis on computer-mediated communication has increased in higher education, it also influences how courses are taught. Therefore, conditions for both students and teachers for participating in higher education have changed. This general change in higher education prompted supervisors to also embrace what this article calls 'online supervision' (e.g., Crossouard 2008; de Beer and Mason 2009; Price and Money 2002; Sussex 2008). Such supervision embraces the mediation of oral and written communication between students and teachers via computers. To narrow its focus, this article explores online supervision of undergraduate students' dissertation work. The level of analysis consists of written communicative exchanges that emerge between students and supervisors in the practice of supervision. The study-object is a three-way relationship-specifically, the relationship is between the supervisor's (teacher's) written utterances on drafts of the students' (learners') dissertation work (produced knowledge) (Lee and Green 2009). The goal is to contribute to "the development of supervision skills" (Drennan and Clarke 
2009, p. 496), which Drennan and Clarke (2009) believe "should be a priority of the university" (p. 496).

Before discussing how the current study was conducted, the background on the practice of online supervision follows. However, studies of online supervision in undergraduate students' dissertation work are rarely found. Therefore, it is an area in need of research (Heinze and Heinze 2009), as well as a reason that this background also discusses other higher education studies. Subsequently, a theoretical framework that discusses the dialogical ideas of Bakhtin (1935/1981, 1953/1986) as a suitable departure to study communicative exchanges, such as online supervision, will be presented. In the next section, this paper will describe the empirical framework, which consists of descriptions of the studied educational setting and methods for sampling and analysing the empirical data. The following section offers an analysis of the written communication uttered by supervisors. Finally, the article ends with conclusions from the current study about how supervisors could balance supporting the student and shaping the dissertation (Anderson et al. 2006).

\section{Participation in online supervision}

During the first decade of the twenty-first century, scholars discussed the relationship between technologies and participation in the practice of supervision (e.g., Crossouard 2008; de Beer and Mason 2009; Dysthe et al. 2006; Mac Keogh 2006; Price and Money 2002; Sussex 2008). In designing courses that include online supervision, teachers make choices that influence the performance of online supervision. They have to choose how to participate in the practice of supervision. Their choices embrace suitable technologies that afford computer-mediated communication, and they embrace how to use these technologies. Sussex (2008) discussed three specific problems in online supervision. The first problem is the degree to which supervisors and students know one another; effective online supervision needs to compensate for the lack of social cues. This problem embraces issues of age, culture, ethnicity, gender, and personality. Second, there is an issue with information exchange. Supervision includes communicating about argumentative, conceptual, factual, personal, procedural, rhetorical, and stylistic issues in research papers. Nevertheless, the same technology is not suitable for all of these issues. Third, online supervision includes issues relating to the information-exchange channel. In online supervision, there is a need to choose a proper communication technology (Sussex 2008).

Another problem in the practice of online supervision is the intersection between students/supervisors and their locations. Scholars discuss three types of links: remote, traditional, and semi-remote (Price and Money 2002). Participation in remote supervision embraces a physical separation between students and supervisors. Supervision includes at least two geographical locations. Overall, in remote supervision, communication depends on technologies. In traditional supervision, students and supervisors are geographically colocated. This means that participation takes place on campus, usually during a one-to-one meeting (de Beer and Mason 2009; Mac Keogh 2006). Semi-remote supervision is a typical blended-learning idea that embraces a combination of remote and traditional supervision (Crossouard 2008; Jaldemark and Lindberg 2012). Therefore, online supervision can be a remote practice, as well as a semi-remote practice.

Crossouard (2008) discussed a doctoral programme with semi-remote characteristics. In this program, supervision included the use of computer conferences, e-mail, and face-toface workshops. These features were embraced in a formative assessment process, which included students' and supervisors' discussing drafts of students' dissertation work. In the 
semi-remote design, the model of face-to-face supervision and online dialogue were found to enhance "each other and took pressure of the student-supervisor relationship, making its personal chemistry less critical" (Crossouard 2008, p. 62).

Similar results were found by Dysthe et al. (2006) in their study of master students. In their case, the blending was about supervision groups with supervisors and their students, self-organized student groups without supervisors, and individual supervision between the supervisor and her or his student. In addition to the decreased importance of personal chemistry between student and supervisor, they also found that "less time was spent on individual supervision'... [and that such] controversies were less threatening" (Dysthe et al. 2006, p. 311).

A few studies of undergraduate students' dissertation work have focused on the link between the involved agents and the technologies included in the practice of supervision (e.g., Heinze and Heinze 2009; Källkvist et al. 2009). The motivation behind the study by Källkvist et al. (2009) was to support undergraduate students as they wrote a research report. They introduced electronic portfolios into the design of the course. The supervisors emphasised that the tools incorporated into the course design facilitated remote and efficient guidance for individual students, as well as on a collective level of supervision. Heinze and Heinze's (2009) suggested the use of electronic comments and tracking changes for improving formative assessment in undergraduate students' dissertation work. Moreover, the practice of supervision could also benefit from technologies that facilitate social aspects of supervision-for example, computer conferences, chat, and social network sites.

\section{Theoretical framework}

The studies mentioned above mainly comprised online supervision in terms of written utterances-for example, through chat, computer conference, or e-mail (e.g., Crossouard 2008; Heinze and Heinze 2009; Källkvist et al. 2009). Theoretically, these utterances form part of the communicative exchanges performed in the practice of supervision. These exchanges could be discussed as being inseparable from the surrounding environment, meaning that they relate to cultural, ecological, historical, and social aspects of the surrounding conditions under which online supervision emerges. This means that supervision is an emergent communicative phenomenon that relates to the past, current, and future states of its practice. From such a theoretical departure, tools mediate communicative exchanges between students and supervisors (e.g., Rogoff 2003; Säljö 1999; Wertsch 2007).

Dysthe et al. (2006) utilised Lave and Wenger's (1991) distinction between 'teaching curriculum' and 'learning curriculum'. Teaching curriculum is directing and regulatory from the supervisors' perspective, while learning curriculum is more about a situationbound knowledge exchange from the learners' perspective. In this article, the essence of the teaching curriculum seems to be relevant because it is about the supervisor's perspective on the student's actual draft in the middle of a supervisory process.

This feature of participation in the practice of online supervision, embracing toolmediated communicative exchanges, suits the dialogical ideas of Bakhtin (1935/1981, 1953/1986). In the 1930s, he claimed that understanding and response "diametrically merged and mutually condition each other; one is impossible without the other" (Bakhtin 1935/1981, p. 282). An understanding of a communicative practice from such a perspective needs an analytical unit that reflects this inseparable character of the communicative 
exchange. According to Bakhtin, the utterance is such a unit of communication; he emphasised that a sentence is "a unit of language, as distinct from the utterance as a unit of speech communication" (Bakhtin 1953/1986, p. 73). Moreover, this unit of communication also has the characteristic of having a relation to preceding and subsequent utterances. The boundaries of the utterance are "determined by a change of speaking subjects. Such a change, framing the sentence on both sides, transforms the sentence into an entire utterance" (Bakhtin 1953/1986, p. 73). After becoming a complete utterance, it is a link in the chain of communication. As such a link, the utterance "has the capability of determining the active responsive position of the other participants in the communication" (Bakhtin 1953/1986, p. 82). This idea of an utterance being a link in the chain of communication also includes the possibility for the listener to respond.

Subsequently, and in accordance with Dysthe et al. (2006), this article applies the distinction that Bakhtin (1935/1981) made between 'authoritative' and 'internally persuasive discourse'. The meaning of the 'authoritative' utterances is that the listener is dependent upon it and, therefore, is expected to unconditionally embrace its meaning. 'Internally persuasive discourse' is more about reasoning and is, therefore, integrated with the recipient's own opinion. Dysthe et al. (2006, p. 303) claimed that "ideally supervision provides internally persuasive discourse, but research has shown that it is often perceived as "the authoritative word"'. While the analysis of this article embraces supervisors' advising words on drafts of students' dissertations, students might perceive these utterances as authoritative. However, in an ideal situation, they are perceived as internally persuasive words. Nevertheless, the supervisors' task is to give these utterances with the aim of formatively assessing students' work on their dissertations.

Thus, in online supervision, the communicative exchange of utterances between students and supervisors could be understood as a search for shared meaning. In this search, meaning-making is "a bridge between the speaker and the listener, the writer and the reader" (Dysthe 2002a, p. 341). Expressed in other words, the dialogue that emerges between the students and the supervisors is a meaning-making process focused on learning how to write a dissertation. In this process, the utterances of supervisors are at the heart of the practice of supervision. In the next section, the empirical framework of the study is presented.

\section{Empirical framework}

\section{Educational setting}

The studied educational setting was a bachelor programme in behavioural science at a Swedish university. Enrolled students chose either to study one of two specialisations: human science or computer science. These specialisations have in common the fact that they are studies in the disciplines of education and psychology. The programme either enrolled the students in a campus mode or in a distance-based mode. This study focuses on the students enrolled in the distance-based mode. These students met at a campus two or three times each semester. Otherwise, teaching was based on the applications that were supported by the university, which embraced blogs, chat, computer conferences, desktop video conferences, and e-mail.

The examples of the data presented in this article come from a 15-credit basic course in the discipline of education. The course took place during the second semester, and students worked during a 20 -week period, half-time, with an undergraduate dissertation. The 
dissertation course included a structured working process comprising 13 phases. A 14-page study guide described the working process of the course (Jaldemark 2012). Six of these phases comprised a process of interplay on drafts of students' dissertation work. These six drafts were submitted to the learning management system (LMS), from which the supervisor downloaded and commented on the text using the reviewing function in the word processor. At each occasion, the supervisor then submitted these written utterances to the LMS within two working days.

The educational design of the working process was built on two different but interrelated principles: group dialogues and open and public exchanges of information. In short, these principles should foster the development of learning communities and encourage students to collaborate and learn from one another's work (Carlén and Jobring 2005; Lave and Wenger 1991; Vygotsky 1934/1987). By supporting work in a collaborative manner, these principles should scaffold students' learning of the research process. Moreover, group dialogues and open and public exchanges should also provide students with an opportunity to participate in formative assessment processes (Price et al. 2007). In the educational design, the meaning of such formative assessment is "to support learning" but not grading (Crossouard 2008, p. 52). The educational setting was designed to support this collaborative learning in different ways. For example, all drafts of the dissertation and comments from the supervisors were available to all students, so there were opportunities for students to learn from one another's supervision process. In effect, this design embraced the idea of learning from supervisors' advice given on every draft of all students' work.

Moreover, students were encouraged to write collaboratively. Therefore, most of the students wrote their dissertations in pairs, with a few exceptions of single-student dissertations. The difference between writing in pairs and writing individually lies in having or not having a co-author to collaborate with during the research process, the writing process, and the supervision process. Students also worked in study groups, where each group consisted of 10-20 students and was led by a supervisor. Each group researched a specific theme related to the supervisor's area of expertise. In these groups, students were encouraged to help one another-for example, by suggesting suitable references or proofreading one another's work. Overall, the implication of this educational design entails interplay between individual writing and collaborative learning.

\section{Sampling and analysis}

The greater research project (see also, Jaldemark 2012; Jaldemark and Lindberg 2012) to which this study belongs aims to analyse semi-remote online supervision. In that project, the research design is influenced by the single-case study approach. Such an approach provides the possibility of gaining insight into the practice of online supervision. The partproject reported in this article focused on one course, as well as its online supervision, that was "looked at in depth, its context scrutinized, [and] its ordinary activities detailed" (Stake 1994, p. 237). This means that it is sensitive to the specific conditions of the online supervision. These conditions embrace descriptions of critical phases of the online supervision and the sampling procedure, which focus on the written utterances of the supervisors in the most suitable phases of the working process: two of the six phases that included drafts of the dissertation. These phases were chosen because they could provide rich information about online supervision (Jones 1999; Patton 2002). Therefore, this article included utterances from supervisors on the third and fourth drafts of the students' dissertation work. These drafts include students pondering over: their choice of scientific 
problem; how they should structure and present their research review; how to deal with methodological issues. Students' third drafts were approximately six pages long. Because the comments from the supervisor were received, and through the use of the opportunity to learn from comments on other students' drafts, drafts of papers grew to about 10 pages for the fourth supervision occasion.

The course included a total of 33 dissertations, of which 29 had come so far in the supervising process that they could be part of the sample of drafts for data collection for this article. From these 29 drafts, two were excluded because they were supervised by one of the authors of this article; consequently, the sample included 27 dissertations.

The selection was made in two steps. In these steps of the study, cluster sampling (Bryman 2008) was applied, where each cluster consisted of a single supervisor. The dissertations were then randomly chosen within each supervisor's study group. Firstly, one dissertation from each cluster was chosen. Of these dissertations, the third and fourth drafts were included in the study. In the following analysis, all of the supervisors' utterances in the drafts were categorised. Influenced by an inductive matrix approach, the following analysis embraced categorisation of the supervisors' utterances of the dissertation drafts (Miles and Huberman 1994). Owing to the result of the categorisation, as well as a pattern consisting of different qualities and degrees of identifications in the supervisors' utterances, this step gave rise to the need to first compile all utterances in terms of qualities and identifications and then to examine this compilation. However, additional data were needed to strengthen the credibility of the study. Therefore, in the second step, the study included an additional selection of two dissertations from each of the four clusters. Thus, in total, the analysis embraced 24 drafts from 12 dissertations supervised by four supervisors. Of these drafts, each supervisor was responsible for three dissertations.

To enhance trustworthiness, the study included coding from two researchers. They first coded the utterances individually. Then, to enhance and reach a high level of trustworthiness, both researchers collaboratively discussed their codings and reached a consensus decision on the coding of each of the supervisors' utterances.

Linked to trustworthiness is the study's credibility (Graneheim and Lundman 2004) that is, issues concerning the degree of focus in the research. Credibility refers to how well the intended focus is addressed in the sampling and data analysis. In the current study, credibility was secured in multiple ways. Supervision is a practice related to everyday work in higher education. Therefore, the sample consisted of supervisors with a variety of experience in research work and experience in teaching and supervising in higher education. Of the four supervisors, two of them were women. Their ages varied between 45 years old and 66 years old. Adding to the study's credibility, the researchers have between 16 and 20 years of experience supervising dissertation work at the undergraduate level of higher education. Finally, using utterances as the measurement through which to examine supervision ensures that the link between the educational setting, the supervisors, and the students were present in the analysis. This is illustrated in the inclusion of quotations from the drafts.

Transferability (Graneheim and Lundman 2004; Krefting 1991), another issue in reaching a high level of trustworthiness, refers to the possibility of transferring the results to other groups or settings. Application of quotations from the analysed utterances and rich descriptions of the educational setting are two ways to emphasise transferability. The quotes should help the reader to understand the proposed theory's link to the practice of supervision. References to external sources for even richer descriptions of the educational setting and conditions for the study serve to help the reader to enhance transferability to other educational settings or student cohorts of supervision. 
The quoted dissertations have been coded, which is shown after each quote in the results section. Numbers 3, 4, and 6 were supervised by one supervisor; 8, 9, and 12 by another; numbers 15,16 , and 19 by a third supervisor; and 15,26 , and 30 by the fourth supervisor. Illustrated by the following quote, the encoding of the utterances given in the results section follows the following principles: 'Define learning disabilities already here! (8:3:1)', where $8=$ dissertation number in the analysis, $3=\mathrm{draft}$ number, and $1=$ number of the utterance given in the analysed draft.

In summary, the supervisors produced 541 utterances. This gives an average of about 135 utterances per supervisor. The difference in the number of utterances from the supervisors was $93,106,109$, and 233. Of these 541 utterances, $78 \%$ of them were deemed valuable for the data analysis. The other $22 \%$ were excluded if they: a) dealt with the template in which the dissertation was written, rather than its content; and b) if they could be linked to the appendices in the dissertation that were pre-excluded from the analysis. This means that the excluded utterances were not directed toward the written body text. The $78 \%$ of utterances included in the analysis are equivalent to 423 utterances. The number of utterances varies between the supervisors: 69, 102, 66, and 186.

\section{The written communication uttered by the supervisors}

This section contains patterns of supervisors' written communication on students' dissertation work. The analysis reveals a pattern that could be described as a typology of supervisors' written utterances. This typology consists of qualitatively distinct utterances and different types of identifications. In this section, the typology is illustrated with the help of a matrix. This typology is discussed below, and the two steps shown in the analysis section help to illustrate its construction. In step one, the categories are explained; see Table 1. In step two of the analysis, the matrix is filled with empirical data taken from the supervisors' utterances. Table 2 illustrates the typology with the help of quotes from the supervisors; finally, Table 3 presents quantitative data.

\section{A typology of communicative qualities and identifications}

The first analysis of two drafts from four dissertations resulted in the preliminary typology presented in Table 1. This typology comprises qualitatively distinct utterances and their relation to different types of identifications. Table 1 illustrates this typology in the column and row headings. Below, the meaning of these headings unfolds.

The columns of Table 1 contain four qualitatively different utterances: comments, points of view, instructions, and questions. Comments are statements that certainly express personal attitudes, but are more reflective than instructive in their nature. This means that

Table 1 Qualitatively distinct utterances in relation to different types of identifications

\begin{tabular}{lllll}
\hline Identifications & Qualities & & \\
\cline { 2 - 4 } & Comments & Points of view & Instructions & Questions \\
\hline $\begin{array}{l}\text { Recommendation } \\
\text { Development } \\
\text { Problematising }\end{array}$ & & & \\
\hline
\end{tabular}


Table 2 The intersection of qualitatively distinct utterances in relation to different types of identifications

\begin{tabular}{|c|c|c|c|c|}
\hline \multirow[t]{2}{*}{ Identifications } & \multicolumn{4}{|l|}{ Qualities } \\
\hline & Comments & Points of view & Instructions & Questions \\
\hline Recommendation & $\begin{array}{l}\text { (a) Reflection of } \\
\text { supervised text } \\
\text { and an advocate } \\
\text { for something } \\
\text { specific }\end{array}$ & $\begin{array}{l}\text { (d) Advocacy } \\
\text { position on } \\
\text { something } \\
\text { specific }\end{array}$ & $\begin{array}{l}\text { (g) Advocacy } \\
\text { instruction }\end{array}$ & $\begin{array}{l}\text { (j) A question that } \\
\text { has an advocacy } \\
\text { intonation }\end{array}$ \\
\hline Development & $\begin{array}{l}\text { (b) Reflection of } \\
\text { supervised text on } \\
\text { the development } \\
\text { of a detail from } \\
\text { what already } \\
\text { exists }\end{array}$ & $\begin{array}{l}\text { (e) Position to } \\
\text { develop a detail } \\
\text { from what } \\
\text { already exists }\end{array}$ & $\begin{array}{l}\text { (h) Instruction to } \\
\text { develop a detail } \\
\text { from what } \\
\text { already exists }\end{array}$ & $\begin{array}{l}\text { (k) A question that } \\
\text { has an intonation } \\
\text { to develop a } \\
\text { detail from what } \\
\text { already exists }\end{array}$ \\
\hline Problematising & $\begin{array}{l}\text { (c) Reflection of } \\
\text { supervised text } \\
\text { about the } \\
\text { underlying } \\
\text { circumstances in } \\
\text { relation to one's } \\
\text { own or someone } \\
\text { else's idea }\end{array}$ & $\begin{array}{l}\text { (f) Position related } \\
\text { to the underlying } \\
\text { circumstances in } \\
\text { relation to one's } \\
\text { own or someone } \\
\text { else's idea }\end{array}$ & $\begin{array}{l}\text { (i) Instructions } \\
\text { regarding the } \\
\text { underlying } \\
\text { circumstances in } \\
\text { relation to one's } \\
\text { own or someone } \\
\text { else's idea }\end{array}$ & $\begin{array}{l}\text { (1) A question } \\
\text { regarding the } \\
\text { underlying } \\
\text { circumstances in } \\
\text { relation to one's } \\
\text { own or someone } \\
\text { else's idea }\end{array}$ \\
\hline
\end{tabular}

Table 3 The relationship between qualities and identifications in the utterances

\begin{tabular}{lcccccc}
\hline Identifications & Qualities & & & & \\
\cline { 2 - 7 } & Comments & Points of view & Instructions & Questions & Total & Percent \\
\hline Recommendation & 12 & 70 & 63 & 13 & 158 & 37 \\
Development & 9 & 49 & 49 & 49 & 156 & 37 \\
Problematising & 38 & 23 & 14 & 34 & 109 & 26 \\
Total & 59 & 142 & 126 & 96 & 423 & 100 \\
Percent & 14 & 34 & 30 & 23 & 100 & \\
\hline
\end{tabular}

comments are more descriptive than they are prescriptive. Points of view are intended to convey particular ideas or assessments about specific issues, and as such, they are more prescriptive than they are descriptive. Instructions refer to indications of appropriate approaches in a particular context; hence, they are highly controlling of something specific. A question can first be formulated for different reasons; the most common is to find an answer. Secondly, a question can be formulated with a more or less insinuating tone. In such cases, it is usually not that a question should be answered, but rather, a question is intended to ask for something that lies between the lines of the words. Therefore, a question has the potential to combine the use of an authoritative demand with letting the student independently come up with a suitable solution to a specific problem in the text.

These types of utterances distinguish between the degree of authority and internal persuasiveness (Bakhtin 1935/1981). Comments are mostly internally persuasive because they reflect the written text in a way that has no direction or instruction for a specific action. Another way of expressing this is that comments speak to the student's own assessment. This means that the student needs to decide the appropriate action based on her 
or his own thinking. Points of view have a greater degree of authority because they contain specific content in relation to a pointed question of fact. Instructions are even more authoritative than points of view are because they provide a direct indication of what needs attention. However, they do not always include how to revise the text. Questions may be perceived as mostly authoritative because they refer to something specific, but without that, the requested content necessarily is expressed. Their authority lies in the fact that they are referring back to something specific. This could be a certain concept, a choice, or an aspect.

In summary, the difference between the qualities in Table 1 is that a comment is descriptive without any assigned action, a point of view is a judgment in a specific direction of action, an instruction is an authoritatively assigned task, and a question refers generally to a specific detail in the text.

The rows in Table 1 show that every utterance may differ concerning the level of identification. This means a spread between lower and higher degrees of identification, such as a recommendation - that is, to give an opinion in favour of something; a development - that is, adding more details about something and explaining how these details may be related to one another and to the topic; or a problematisation, which means a call on the student to develop her or his own or someone else's idea of (possible) underlying conditions.

The next step of the analysis included additional drafts from eight dissertations. The analysis of these drafts confirmed the typology. By combining the columns and rows in Table 1, the typology extends to a potential theory and, therefore, embraces the intersections of the supervisors' qualitatively different utterances and the different levels of abstractions of these utterance identifications.

Each intersection in Table 2 is marked with a lowercase letter that refers to empirical quotes below. The table shows how the supervisors' utterances in the quality of comments can vary between: (a) advocating for something specific; (b) asking for the development of a detail from what is already there; or (c) advocating that the student pays attention to underlying circumstances. The following quotes are examples of utterances from three supervisors that contain multiple degrees of identifications:

(a) That is dealt with in the review and seems appropriate (3:3:6).

(b) Develop. What do they say that is relevant to your study? How did they come up with that? (26:4:15).

(c) Motivate in a different way based on your frames... (15:3:5).

Regarding the quality point of view, the utterances of the supervisor distinguish between: (d) advocating for a standpoint about something specific; (e) declaring an opinion and asking the author to develop a detail from what is already there; or (f) highlighting the clarification of the underlying circumstances in relation to a specific idea. Points of view with various degrees of identifications may look like the following utterances taken from three supervisors:

(d) Can be used as paragraph 1 in the introduction $(6: 3: 2)$.

(e) Spelling (9:3:42).

(f) I would like to see more about what 'effective skill development' is (19:4:7).

Although instructions for an appropriate scientific approach may be, more or less, identified in supervisors' utterances, they can involve anything from: (g) an authoritative instruction; (h) a less authoritative instruction to develop a detail from what already exists; 
or (i) a more internal persuasive instruction that refers to underlying circumstances. Examples of three supervisors' degrees of identifications of instructions are as follows:

(g) Move to the method chapter, about selection (4:4:4).

(h) Define learning disabilities already here! (8:3:1).

(i) Wrong reference. Weave together the text with your own thoughts and the red thread (25:4:15).

As with the other utterances, questions may also include different degrees of identifications. A question can include: (j) advocacy intonation; (k) intonation about developing something; and (l) a pronounced question about the recognition of an underlying circumstance. The exemplifying utterances below from different supervisors contain these degrees of identifications:

(j) Why do you define a teacher? The concepts above, I think, are obvious (19:4:8).

(k) Why these selections? (4:4:21).

(1) This is about previous research...? (6:4:14).

The quotations above, a-l, exemplify the distribution of the supervisors' utterances over the columns and the rows in Table 2. All utterances can be connected to a teaching curriculum, but a reflective and strategic supervisor can vary the qualities and identifications in her or his utterances in such a way that the specific utterances may have a stronger or weaker authoritarian intonation, while others have an internally persuasive intonation.

However, the utterances from the supervisors are not equally distributed. This inequality is distributed among supervisors, as well as between qualities, identifications, and their intersections. The relationship between qualities and identifications in the study is as follows:

Table 3 shows that the ratios of the utterances' different qualities are 14, 34, 30, and $23 \%$. The largest proportion was found in the point of views and the lowest in the comments. There is a more even distribution between different degrees of identifications. Recommendations and development comprise $37 \%$ and problematisation $26 \%$.

\section{A theory of communicative exchanges in supervision of dissertations}

The purpose of this article was to focus on supervisors' written online communication about drafts of students' dissertations. This purpose was investigated by identifying and analysing differences in supervisors' written utterances regarding drafts of undergraduate students' dissertation work.

The use of written utterances is one of the supervisor's most important tools. It is, therefore, important to remember that through the application of written utterances in the drafts of the dissertation, the supervisor exercises a unique influence on the student's work by linking her or his opinions towards the student's specific situation. However, it is crucial to emphasize that the analysis is performed in the middle of a supervision process, which means that the utterances from the supervisor that we analyse constitute a reaction to a draft that the student has sent to the supervisor. In the next stage of the process, the students' reactions to the supervisor's statements will be included in the next draft, which, in turn, will be submitted for supervision at a later date. This communicative exchange can, in turn, be understood as an aspect of power. Therefore, the supervisor has a multidimensional responsibility to support knowledge development in scientific writing and to do so in a way that leads to academically desirable results (Anderson et al. 2006). 


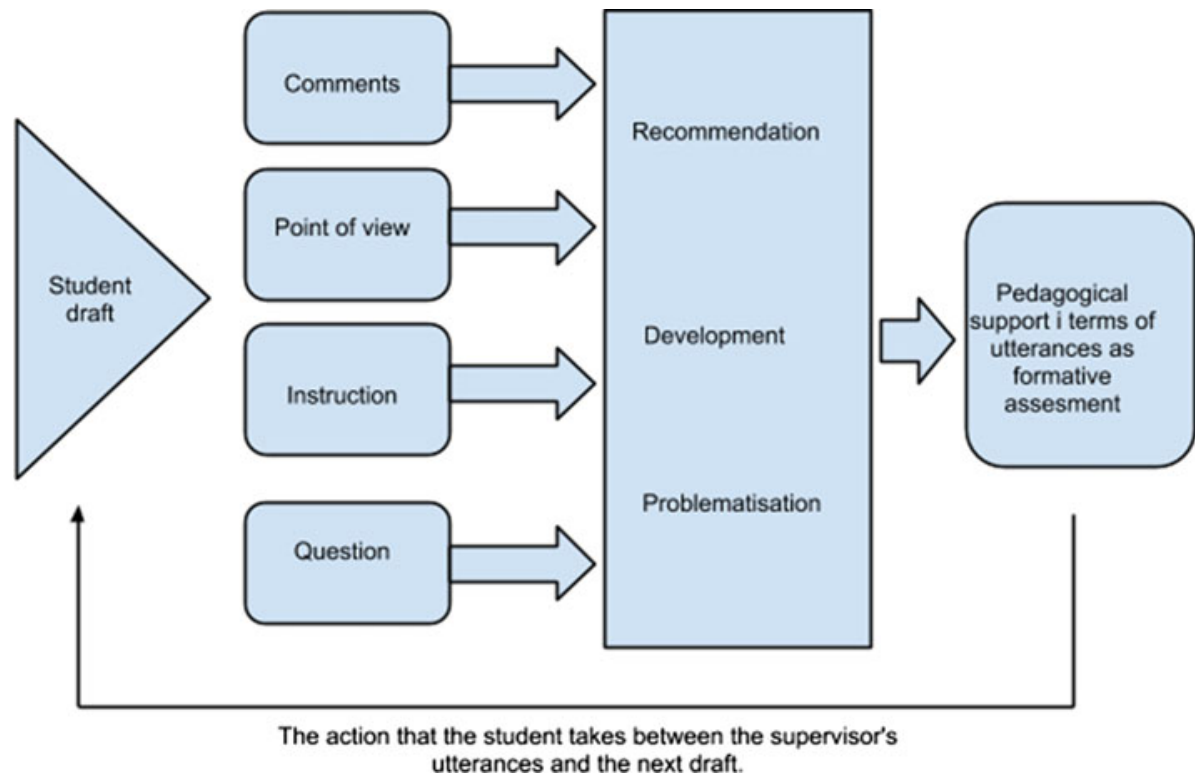

Fig. 1 The supervision process on a draft of dissertation. From the supervisor's receiving and later commenting on a student's draft to the student's revision and submission of a new draft

Figure 1 illustrates that the formative assessments that the supervisors conduct are written utterances in terms of qualities and identifications. The study shows that the quality of supervisors' utterances embraces the difference between the application of comments, points of view, instructions, and questions. Supervisors use comments to increase students' independent responsibility for their work and are, as such, open for the students' own words (Dysthe et al. 2006). Points of view or instructions have a diminishing character regarding the students' own responsibility. Points of view and instructions direct students' thinking in an authoritative way, instead of increasing their independency. Points of view are more implicit than instructions are. The results also show that a question can be used in different ways: as an invitation, an instruction, or an inquiry. However, it is up to the student to closely read between the lines to interpret the message. This also means that supervisors can use questions formulated on the basis of a teaching curriculum to demand students to take independent actions-i.e., supervisors allow students from a relatively authoritative supervision to independently come up with suitable solutions to identified problems. Nevertheless, this depends heavily on the wording of the questions that they pose.

Three types of identifications were revealed in the study: recommendations, developments, and problematisations. These types differ in that one is an opinion in favour of something, one asks for more details about something, and one is an explanation of how these details may be related to each other and the topic in question and a request to the student to develop her or his own or someone else's idea of underlying conditions. Table 2 shows that it is possible for supervisors who are aware of these different types of utterances to strategically combine and vary their utterances.

The ability to strategically combine and vary different utterances makes it possible to update our typology to a theory. Such a kind of strategic combination and variation can 
serve several purposes. First, it can be about the pedagogical sense to support a student's development as a writer. Second, it may be a question of guiding the student when collecting some type of theoretical or empirical information. Third, it can be about supporting the students' reflections on the relationship between the form and content of their dissertations. Such strategic variation can be understood as an invitation to the students to use their own words to revise their texts and, through such a strategy, to bridge the difference between 'talking about' academic writing as a phenomenon and 'talking within' academic writing as a craft (Dysthe et al. 2006; Lave and Wenger 1991).

The here outlined theory is enlightening because if the supervisor of a course about scientific writing, for example, would like to increase the degree of student autonomy, he or she could strategically do that in two stages. Firstly, it can be done by changing the quality of an utterance-for example, by increasing the number of comments and reducing the number of points of view and instructions. Secondly, it can be done by combining the chosen quality with the most suitable identification-i.e., recommendation, development, or problematisation.

This could, with reference to Dysthe et al. (2006), be understood as a tendentious combination of the meaning in Lave and Wenger's (1991) concepts of teaching curriculum and learning curriculum. The logic of the combination is that the supervisors use their authoritative utterances for directing and regulating with the aim of reaching the recipients' own opinions. This can, with the use of progressive supervision in the long run, partially end up in a knowledge exchange with the student, instead of having the supervisor to only instruct her/him.

The results implicate the importance of awareness among supervisors in online supervision, particularly regarding the nature of the qualities and the identifications of their written utterances when supervising students' academic writing. Such awareness makes it possible for supervisors to strategically emphasise students' independence and guide students through the writing process by applying a balanced mix of qualities and identifications. Reaching a balanced mix of such utterances in online supervisions may be very valuable in the process of supervising dissertation work and could overcome the "duality of supporting and shaping", as described by Anderson et al. (2006, p. 166).

Two limitations of the study should be pointed out. First, this study only includes empirical data collected from one university, and second, the sample includes only one higher education programme. However, the data embraces utterances from several supervisors with diverse training and experiences.

The preliminary results of the research project of online supervision also suggest scrutinising how students perceive supervisors' written utterances on their drafts. That task will, together with an analysis of how supervisors perceive their own utterances, be more closely examined in further studies. Such studies could focus on how the dialogue between students and supervisors intersect in drafts of students' dissertations.

\section{References}

Allen, I. E., \& Seamen, J. (2010). Class differences: Online education in the United States, 2010. http:// sloanconsortium.org/publications/survey/pdf/class_differences.pdf. Accessed September 29, 2011.

Allen, I. E., \& Seamen, J. (2011). Going the distance: Online education in the United States, 2011. http://www.onlinelearningsurvey.com/reports/goingthedistance.pdf. Accessed August 24, 2012.

Anderson, C., Day, K., \& McLaughlin, P. (2006). Mastering the dissertation: Lecturers' representations of the purposes and processes of master's level dissertation supervision. Studies in Higher Education, 31(2), 149-168. 
Bakhtin, M. M. (1935/1981). Discourse in the novel. In M. Holquist (Ed.), The dialogic imagination: Four essays (pp. 259-422). Austin: University of Texas Press.

Bakhtin, M. M. (1953/1986). The problem of speech genres. In C. Emerson \& M. Holquist (Eds.), Speech genres and other late essays (pp. 60-102). Austin: University of Texas Press.

Bryman, A. (2008). Social research methods (3rd ed.). Oxford: Oxford University Press.

Carlén, U., \& Jobring, O. (2005). The rationale of online learning communities. International Journal of Web Based Communities, 1(3), 272-295.

Crossouard, B. (2008). Developing alternative models of doctoral supervision with online formative assessment. Studies in Continuing Education, 30(1), 51-67.

de Beer, M., \& Mason, R. (2009). Using a blended approach to facilitate postgraduate supervision. Innovations in Education and Teaching International, 46(2), 213-226.

Drennan, J., \& Clarke, M. (2009). Coursework master's programmes: The student's experience of research and research supervision. Studies in Higher Education, 34(5), 483-500.

Dysthe, O. (2002a). The learning potential of a web-mediated discussion in a university course. Studies in Higher Education, 27(3), 339-352.

Dysthe, O. (2002b). Professors as mediators of academic text cultures: An interview study with advisors and master's degree students in three disciplines in a Norwegian university. Written Communication, 19(4), 493-544.

Dysthe, O. (2007). How a reform affects writing in higher education. Studies in Higher Education, 32(2), 237-252.

Dysthe, O., Samara, A., \& Westrheim, K. (2006). Multivoiced supervision of master's students: A case study of alternative supervision practices in higher education. Studies in Higher Education, 31(3), 299-318.

Frankland, M. (1999). The master/apprentice model for the supervision of postgraduate research and a new policy for research education. Australian Universities' Review, 42(1), 8-11.

Fraser, R., \& Mathews, A. (1999). An evaluation of the desireable characteristics of a supervisor. Australian Universities' Review, 42(1), 5-7.

Graneheim, U. H., \& Lundman, B. (2004). Qualitative content analysis in nursing research: Concepts, procedures and measures to achieve trustworthiness. Nurse Education Today, 24(2), 105-112.

Heinze, A., \& Heinze, B. (2009). Blended e-learning skeleton of conversation: Improving formative assessment in undergraduate dissertation supervision. British Journal of Educational Technology, 40(2), 294-305.

Högberg, M., Eriksson, Å., Bäcklund, I., \& Gustafsson, C. (1999). Mästarprov eller mardröm: Studenters uppfattningar om examination av självständigt arbete. Högskoleverkets skriftserie (Vol. 1998:8). Stockholm: Högskoleverket.

Jaldemark, J. (2012). Boundless writing: Applying a transactional approach to design of a thesis course in higher education. In A. D. Olofsson \& O. J. Lindberg (Eds.), Informed design of educational technologies in higher education: Enhanced learning and teaching (pp. 135-151). Hershey: IGI Global.

Jaldemark, J., \& Lindberg, O. (2012). Technology-mediated supervision of undergraduate students' dissertations. Studies in Higher Education. doi:10.1080/03075079.2011.626851.

Jones, S. (1999). Studying the net: Intricacies and issues. In S. Jones (Ed.), Doing internet research: Critical issues and methods for examining the net (pp. 1-27). Thousand Oaks: Sage.

Källkvist, M., Gomez, S., Andersson, H., \& Lush, D. (2009). Personalised virtual learning spaces to support undergraduates in producing research reports: Two case studies. The Internet and Higher Education, $12(1), 25-44$.

Kolmos, A., Kofoed, L., \& Du, X. (2008). PhD students' work conditions and study environment in university- and industry-based $\mathrm{PhD}$ programmes. European Journal of Engineering Education, 33(5), 539-550.

Krefting, L. (1991). Rigor in qualitative research: The assessment of trustworthiness. The American Journal of Occupational Therapy, 45(3), 214-222.

Lave, J., \& Wenger, E. (1991). Situated learning: Legitimate peripheral participation. Cambridge: Cambridge University Press.

Lee, A., \& Green, B. (2009). Supervision as metaphor. Studies in Higher Education, 34(6), 615-630.

Mac Keogh, K. (2006). Supervising undergraduate research using online and peer supervision. In M. Huba (Ed.), 7th International Virtual University Conference, Bratislava, Slovakia, 14-15 December 2006 (pp. 19-24). Bratislava: Technichal University Bratislava.

Miles, M. B., \& Huberman, A. M. (1994). Qualitative data analysis: An expanded sourcebook (2nd ed.). Thousand Oaks: Sage.

Parker, R. (2009). A learning community approach to doctoral education in the social sciences. Teaching in Higher Education, 14(1), 43-54. 
Patton, M. Q. (2002). Qualitative research \& evaluation methods (3rd ed.). Thousand Oaks: Sage.

Pearson, M., \& Brew, A. (2002). Research training and supervision development. Studies in Higher Education, 27(2), 135-150.

Price, D. C., \& Money, A. H. (2002). Alternative models for doctoral mentor organisation and research supervision. Mentoring \& Tutoring: Partnership in Learning, 10(2), 127-135.

Price, M., O’Donovan, B., \& Rust, C. (2007). Putting a social-constructivist assessment process model into practice: Building the feedback loop into the assessment process through peer review. Innovations in Education and Teaching International, 44(2), 143-152.

Rogoff, B. (2003). The cultural nature of human development. Oxford: Oxford University Press.

Säljö, R. (1999). Learning as the use of tools: A sociocultural perspective on the human-technology link. In K. Littleton \& P. Light (Eds.), Learning with computers: Analysing productive interaction (pp. 144-161). London: Routledge.

Stake, R. E. (1994). Case studies. In N. K. Denzin \& Y. S. Lincoln (Eds.), Handbook of qualitative research (pp. 236-247). Thousand Oaks: Sage.

Stelma, J., \& Fay, R. (2012). Intentionality and developing researcher competence on a UK master's course: An ecological perspective on research education. Studies in Higher Education. doi:10.1080/ 03075079.2012.709489.

Sussex, R. (2008). Technological options in supervising remote research students. Higher Education, 55(1), 121-137.

Swedish National Agency for Higher Education, \& Statistics Sweden. (2010). Universitet och högskolor: Studenter och examina på grundnivå och avancerad nivå 2008/09. http://www.scb.se/statistik/UF/ UF0205/2008L09D/UF0205_2008L09D_SM_UF20SM1002.pdf. Accessed May 31, 2010.

Vygotsky, L. S. (1934/1987). Thinking and speech (N. Minick, Trans.). In R. W. Rieber, \& A. S. Carton (Eds.), The collected works of L.S. Vygotsky (Vol. 1, Problems of general psychology, pp. 39-285). New York: Plenum.

Wertsch, J. V. (2007). Mediation. In H. Daniels, M. Cole, \& J. V. Wertsch (Eds.), The Cambridge companion to Vygotsky (pp. 178-192). New York: Cambridge University Press.

Wisker, G., Robinson, G., \& Shacham, M. (2007). Postgraduate research success: Communities of practice involving cohorts, guardian supervisors and online communities. Innovations in Education and Teaching International, 44(3), 301-320. 